\title{
Availability of essential medicines in selected public, primary and secondary health care institutions of a rural Sri Lankan district: a spot survey
}

Devarajan Rathish ${ }^{1 *}$, Indika Premarathna', Thiwanka Jayathilake', Chathurika Kandegedara ${ }^{1}$, Kalani Punchihewa', Lakmali Ananda', Thejani Bandara', Channa Jayasumana ${ }^{1}$ and Sisira Siribaddana ${ }^{2}$

\begin{abstract}
Background: Assessment of the availability of essential medicines, in rural areas of countries with free state health care system, is scarce. Dependence on essential medicines among the population in rural sector is considered to be high. Assessing the availability of essential medicines in selected state owned primary and secondary health care institutions of a rural district will help to identify areas where improvement is needed.

Methods: A descriptive cross sectional study, covering selected five primary and one secondary care institutions of a rural Sri Lankan district, was conducted. The national list of essential medicines, Sri Lanka was used as the check list and the guidelines of the WHO-Health Action International were adapted.

Results: The secondary care institution recorded an overall availability of $71 \%$, whereas the average overall availability of the primary care institutions was $56 \%$. Central dispensaries recorded the lowest availability. Lack of availability of medicines needed for the management of chronic kidney disease, snake bite and poisoning was noted.
\end{abstract}

Conclusions: Availability of essential medicines in most of the primary and the secondary care institutions were fairly high. Deficiency in medicines needed for the management of emergencies was noted. A need based annual estimate of medicines based on an essential medicine list is suggested.

Keywords: Availability, Essential medicine, Rural sector, Sri Lanka, Primary care, Secondary care

\section{Background}

Access to medicine is an universal human right, and availability of medicine is a worldwide problem. According to the World Health Organization (WHO), "Essential medicines are those that satisfy the priority health care needs of the population. Essential medicines are intended to be available within the context of functioning health systems at all times in adequate amounts, in the appropriate dosage forms, with assured quality and adequate information, and at a price the individual and the community can afford" [1].

\footnotetext{
* Correspondence: rathishdeva@gmail.com

'Department of Pharmacology, Faculty of Medicine and Allied Sciences,

Rajarata University of Sri Lanka, Saliyapura, Sri Lanka

Full list of author information is available at the end of the article
}

Essential medicines are not available to $33 \%$ of world population and $50 \%$ of people in poorest countries of Africa and Asia [2]. In 2008 a study carried out in 36 developing and middle-income countries reported $29-54 \%$ availability of generic medicines in public sector, where Africa recorded the lowest and America the highest [3]. The availability of 15 generic medicines ranged from $10 \%$ in Yemen to $79 \%$ in Mongolia. All regions showed a lower mean availability in the public sector in comparison to the private sector. In another study availability of essential medicines for chronic diseases was less than $7.5 \%$ in four low and middle income countries but was $28 \%$ in Sri Lanka (SL) [4]. Generic medicines were available and affordable according to a survey carried out over 6 year period in retail pharmacies (semi- 
government and private) of SL [5]. The 2013 SL national survey showed a "fairly high" (50-80\%) availability of selected essential medicines for non-communicable diseases (NCD) in both the private and public sectors [6]. However, another SL study revealed that the availability of key essential medicines for children was "low" (3049\%) in public hospitals [7].

SL's health indicators are comparable with developed countries of Asia and in 2013 SL's total expenditure on health was $3.2 \%$ of the gross domestic product $[8,9]$. Its allopathic health system consist a universal free (non-fee levying) government sector and a fee levying private sector. There are four levels of health care institutions in the country. The primary care institutions are district hospitals (DH), peripheral units (PU), rural hospitals $(\mathrm{RH})$ and central dispensaries (CD). District general hospitals and base hospitals $(\mathrm{BH})$ are secondary care institutions [10].

Previous national surveys have assessed the availability of essential medicines in SL. Published national surveys have de-identified locations in the surveys. Hence we are unable to comment on the urban-rural differences in availability of the essential medicines [5-7]. An abstract published in 2015 revealed Anuradhapura, a rural district of SL, as the district with highest availability (78\%) for drugs used in NCD [11]. To our knowledge studies focusing on availability of drugs in rural districts of SL are scarce. The aim of our study was to assess the availability of essential medicines in selected public health care institutions of a district in rural SL.

\section{Methods}

A descriptive cross sectional study was conducted during the first week of August 2016.

\section{Study setting}

The study was conducted in Anuradhapura district of SL where $95 \%$ of households are rural [12]. Agriculture is the main employment for $55 \%$ of the population [13]. Unemployment rate is $3.1 \%$ [13]. The mean monthly household income of the district is 241 USD, compared to 312 USD for the country [14]. These reasons make the free public health care service as the first choice of the people.

One institution each from the following levels of health care were selected conveniently and visited once for data collection: base hospital, district hospital, peripheral unit, rural hospital and two central dispensaries. The second central dispensary was selected according to WHO-Health Action International (HAI) guidelines. It recommends to survey another institution of the same level if the availability of essential medicine is less than $50 \%$ at the first surveyed institution [15]. Identities of all the above institutions were kept confidential.

\section{Instrument}

Availability of essential medicines was checked using the national list of essential medicines, SL [16]. The first edition was published in 1958 and the fifth in 2014. Clinical needs, disease prevalence, evidence of efficacy, safety and comparative cost-effectiveness are considered by the selection committee in selecting the essential medicines. The list has 29 major categories of drugs. Out of which only 28 were relevant to the primary and secondary care institutions. Under each category there is a core list and in some a complementary list. The core list includes "a list of minimum medicine needs for a basic healthcare system listing the most efficacious, safe and cost-effective medicines for priority conditions" [16]. The complementary list includes "essential medicines for priority diseases, for which specialized diagnostic or monitoring facilities, and/or specialist medical care, and/or specialist training are needed" [16]. The drug information includes the international non-proprietary name of the active moiety, dosage forms, strengths and the level of care at which the drug should be available E.g. Paracetamol tablet: $500 \mathrm{mg}$ (primary, secondary, tertiary and specialist hospitals). This list closely follows the WHO model list of essential medicines [17] with modifications according to the needs of SL.

\section{Data collection, analysis and description of data}

Permission was obtained from the regional director of health services and the relevant heads of the institutions. Availability of essential medicines was checked from the drug stores and the pharmacies of the institutions, using the national list of essential medicines, SL by trained MBBS qualified doctors. According to the WHO-HAI method the specific dose and form was surveyed for availability [15]. As with previous studies the availability of the selected medicine was considered regardless of whether it is innovator, generic or branded generic [4, 6]. A medicine was considered as available only if the data collectors physically saw it [15], drug not being expired and being suitable for use. Data was analyzed using Microsoft excel. Descriptive statistics were used to describe data. Drug availability was described according to earlier national and international surveys; $<30 \%$ : very low, $30-49 \%$ : low, $50-80 \%$ : fairly high and $>80 \%$ : high $[6,18]$. Each dosage form of a particular medicine was considered as separate items. Medicines available in several core or complementary lists of the national list of essential medicines are counted only once [16].

\section{Deviations in methodology from the WHO-HAI recommendations}

According to our objective we plan to find out the availability of essential medicines in selected public health care institutions of a rural SL district using the national 
list of essential medicines, SL. Therefore we differed in the following steps:

- Only availability of drugs was checked and data on pricing was not collected as medicines are dispensed free of charge in state sector [6].

- Only institutions of public primary and secondary care were selected as our objective was to find the availability of essential medicines only in these institutions.

- All drugs included in the national list of essential medicines, SL were checked. We did not restrict the survey to 50 selected medicines as recommended by the WHO-HAI.

- Institutions were selected conveniently rather than randomly. Essential medicines are supposed to be "available within the context of functioning health systems at all times". The aim of the study was to assess the availability of essential medicines in selected public health care institutions of a district in rural Sri Lanka. We do not intend to generalize the data but would only want to highlight the deficiencies in the availability of essential medicines in those selected institutions.

\section{Results}

Numbers for inward, deliveries and out patients for each of the selected institution for the year 2015 were retrieved from the regional director of health service office (Table 1). Availability of essential medicines in $\mathrm{BH}, \mathrm{DH}$, PU, RH and CD-1 were 71, 81, 64, 58 and 32\% respectively. As the total availability at CD-1 was less than $50 \%$, second central dispensary (CD-2) was surveyed as planned. Availability of essential medicines in CD-2 was also less than $50 \%$ (47\%). Availability of individual essential medicines is given as an Additional file 1.

\section{Primary care institutions}

The highest availability of essential medicine was seen in DH (81\%), a primary care institution, the next best was $\mathrm{BH}(71 \%)$, a secondary care institution. Availability was

Table 1 Number of patients for the year 2015 in the selected institutions of Anuradhapura Tables

\begin{tabular}{lcrr}
\hline Institution & Inward & Outpatient & Deliveries \\
\hline BH & 35,207 & 238,235 & 3,219 \\
DH & 10,548 & 170,743 & 95 \\
$\mathrm{PU}$ & 4,191 & 78,714 & 52 \\
$\mathrm{RH}$ & 5,352 & 65,603 & 40 \\
$\mathrm{CD}-1$ & $\mathrm{NA}$ & 15,448 & $\mathrm{NA}$ \\
$\mathrm{CD}-2$ & $\mathrm{NA}$ & 18,858 & $\mathrm{NA}$ \\
\hline
\end{tabular}

$B H$ Base Hospital, DH District Hospital, PU Peripheral Unit, RH Rural Hospital, $C D$ Central Dispensary "fairly high" in PU and RH, whereas it was "low" in both the CDs.

DH showed $100 \%$ availability in analgesics, antiallergics, diuretics, immunologicals, genitourinary medicines, psycho-therapeutic medicines, respiratory medicines, vitamins \& minerals and neonatal care medicines. However it recorded "low" or "very low" availability in medicines affecting the blood (33\%), diagnostic agents (0\%) and ophthalmological preparations (33\%) (Table 2).

PU showed $100 \%$ availability in diuretics and solutions correcting electrolytes. "Low" or "very low" availability at PU was recorded with anticonvulsants (46\%), medicines affecting the blood (33\%), dermatological preparations (44\%), diagnostic agents (0\%), immunologicals (0\%), ophthalmological preparations $(0 \%)$, ENT medicines (22\%) and medicines for neonatal care (0\%) (Table 2).

RH showed $100 \%$ availability in diuretics only, whereas both the CDs failed to show 100\% availability in any of the major categories of essential medicines (Table 2). Diagnostic agent (tropicamide eye drops) was not available at any of the primary care institutions. Immunological (anti-venom serum) and medicines for neonatal care (chlorhexidine for umbillical cord) were only available at DH. Anticonvulsants were not available in both the CDs, whereas CD-2 failed to have any of the antidotes or other substances used for poisoning (Table 2).

\section{Secondary care institution}

$\mathrm{BH}$, the only secondary care institution of the survey, had an overall availability of $71 \%$. It had shown $100 \%$ availability in anaesthetics, anti-allergics, blood products, antiseptics, diuretics, immunologicals, muscle relaxants, genitourinary medicines, solutions correcting electrolytes and medicines for neonatal care. "Low" or "very low" availability was seen in anti-parkinsonism medicines (25\%), dermatological preparations (33\%), diagnostic agents (0\%), ophthalmological preparations (0\%) and ENT medicines (44\%) (Table 2).

\section{Comparison of availability of essential medicines between primary and secondary care institutions}

$\mathrm{BH}$ has a higher overall availability (71\%) than the average overall availability of all primary care institutions (56\%). BH also had most number of drugs (179 vs $\mathrm{DH}-$ 134, PU - 105, RH - 96, CD-1 - 52, CD-2 - 78). Secondary care institution showed higher availability in 18 major categories compared to the primary care institutions. However, secondary care institution has recorded lower availability in analgesics, anti-infectives, dermatological preparations, ophthalmological preparations and vitamins and minerals (Table 2 ).

The secondary care institution failed to have any ophthalmological preparations but 4 out of the 5 primary care institutions (DH, RH, CD - 1, CD - 2) have had 
Table 2 Availability of essential medicines (by major category) Anuradhapura, 2016

\begin{tabular}{|c|c|c|c|c|c|c|c|c|c|c|}
\hline \multirow[t]{2}{*}{ No } & \multirow{2}{*}{$\begin{array}{l}\text { Major categories of } \\
\text { essential medicines }\end{array}$} & \multirow{2}{*}{$\begin{array}{l}\text { Need to be } \\
\text { present at } \mathrm{PCl}\end{array}$} & \multicolumn{5}{|c|}{ Present at each $\mathrm{PCl}(\%)$} & \multirow{2}{*}{$\begin{array}{l}\text { Average } \\
\text { for PCl (\%) }\end{array}$} & \multirow{2}{*}{$\begin{array}{l}\text { Need to be } \\
\text { present at SCl }\end{array}$} & \multirow{2}{*}{$\begin{array}{l}\text { Present at } \\
\mathrm{SCl}(\%)\end{array}$} \\
\hline & & & $\overline{\mathrm{DH}}$ & PU & $\mathrm{RH}$ & CD-1 & CD-2 & & & \\
\hline 1 & Anaesthetics & 4 & $3(75)$ & $3(75)$ & $2(50)$ & $1(25)$ & $2(50)$ & $2.2(55)$ & 17 & $17(100)$ \\
\hline 2 & $\begin{array}{l}\text { Analgesics, antipyretics, } \\
\text { non-steroidal anti-inflammatory } \\
\text { medicines, medicines used to } \\
\text { treat gout and disease modifying } \\
\text { agents in rheumatoid disorders }\end{array}$ & 6 & $6(100)$ & $5(83)$ & $4(67)$ & $3(50)$ & $4(67)$ & $4.4(73)$ & 12 & $8(67)$ \\
\hline 3 & $\begin{array}{l}\text { Anti-allergics and medicines used in } \\
\text { anaphylaxis }\end{array}$ & 8 & $8(100)$ & $7(88)$ & 7 (88) & $7(88)$ & $6(75)$ & $7(88)$ & 8 & $8(100)$ \\
\hline 4 & $\begin{array}{l}\text { Antidotes and other substance } \\
\text { used in poisonings }\end{array}$ & 6 & $3(50)$ & $3(50)$ & $2(33)$ & $1(17)$ & 0 & $1.8(30)$ & 9 & $8(89)$ \\
\hline 5 & Anticonvulsants/anti-epileptics & 11 & $9(82)$ & $5(46)$ & $6(55)$ & 0 & 0 & $4(36)$ & 12 & $6(50)$ \\
\hline 6 & Anti-infective medicines & 24 & $20(83)$ & $19(79)$ & $16(67)$ & $11(46)$ & $17(71)$ & $16.6(69)$ & 47 & $32(68)$ \\
\hline 7 & Anti-migraine medicines & 7 & $6(86)$ & $5(71)$ & $4(57)$ & $5(71)$ & $3(43)$ & $4.6(66)$ & 7 & $6(86)$ \\
\hline 8 & $\begin{array}{l}\text { Anti-neoplastic, immunosuppressive } \\
\text { and medicines used in palliative care }\end{array}$ & N/A & N/A & N/A & N/A & N/A & N/A & N/A & 5 & $3(60)$ \\
\hline 9 & Anti-parkinsonism medicines & N/A & N/A & N/A & N/A & N/A & N/A & N/A & 4 & $1(25)$ \\
\hline 10 & Medicines affecting the blood & 6 & $2(33)$ & $2(33)$ & $2(33)$ & $1(17)$ & $2(33)$ & $1.8(30)$ & 8 & $4(50)$ \\
\hline 11 & $\begin{array}{l}\text { Blood products and plasma } \\
\text { substitutes }\end{array}$ & N/A & N/A & N/A & N/A & N/A & N/A & N/A & 1 & $1(100)$ \\
\hline 12 & Cardiovascular medicines & 26 & $24(92)$ & $21(81)$ & $21(81)$ & $9(35)$ & $16(62)$ & $18.2(70)$ & 27 & $24(89)$ \\
\hline 13 & Dermatological medicines (topical) & 18 & $14(78)$ & $8(44)$ & $6(33)$ & $4(22)$ & $5(28)$ & $7.4(41)$ & 24 & $8(33)$ \\
\hline 14 & Diagnostic agents & 1 & 0 & 0 & 0 & 0 & 0 & $0(0)$ & 1 & $0(0)$ \\
\hline 15 & Disinfectants and antiseptics & 6 & $5(83)$ & $3(50)$ & $4(67)$ & $2(33)$ & $3(50)$ & $3.4(57)$ & 6 & $6(100)$ \\
\hline 16 & Diuretics & 4 & $4(100)$ & $4(100)$ & $4(100)$ & $1(25)$ & $3(75)$ & $3.2(80)$ & 5 & $5(100)$ \\
\hline 17 & Gastrointestinal medicines & 10 & $8(80)$ & $8(80)$ & $9(90)$ & $5(50)$ & $5(50)$ & $7(70)$ & 15 & $12(80)$ \\
\hline 18 & $\begin{array}{l}\text { Hormones, other endocrine } \\
\text { medicines and contraceptives }\end{array}$ & 9 & $8(89)$ & $7(78)$ & $7(78)$ & $4(44)$ & $6(67)$ & $6.4(71)$ & 11 & $8(73)$ \\
\hline 19 & Immunologicals & 1 & $1(100)$ & 0 & 0 & 0 & 0 & $0.2(20)$ & 3 & $3(100)$ \\
\hline 20 & $\begin{array}{l}\text { Muscle relaxant (Peripherally acting) } \\
\text { and cholinesterase inhibitors }\end{array}$ & N/A & N/A & N/A & N/A & N/A & N/A & N/A & 2 & $2(100)$ \\
\hline 21 & Ophthalmological preparations & 3 & $1(33)$ & 0 & $1(33)$ & $1(33)$ & $1(33)$ & $0.8(27)$ & 3 & $0(0)$ \\
\hline 22 & $\begin{array}{l}\text { Medicines acting on the } \\
\text { genitourinary tract }\end{array}$ & 5 & $5(100)$ & $4(80)$ & $4(80)$ & $1(20)$ & $1(20)$ & $3(60)$ & 5 & $5(100)$ \\
\hline 23 & Psychotherapeutic medicines & 7 & $7(100)$ & $6(86)$ & $4(57)$ & $1(14)$ & $2(29)$ & $4(57)$ & 13 & $10(77)$ \\
\hline 24 & $\begin{array}{l}\text { Medicines acting on the } \\
\text { respiratory tract }\end{array}$ & 10 & $10(100)$ & $8(80)$ & $6(60)$ & $2(20)$ & $9(90)$ & $7(70)$ & 10 & $9(90)$ \\
\hline 25 & $\begin{array}{l}\text { Solutions correcting water, } \\
\text { electrolytes and acid-base } \\
\text { disturbances and } \\
\text { parenteral nutrition }\end{array}$ & 7 & $6(86)$ & $7(100)$ & $6(86)$ & $3(43)$ & $4(57)$ & $5.2(74)$ & 10 & $10(100)$ \\
\hline 26 & Vitamins and minerals & 2 & $2(100)$ & $1(50)$ & $1(50)$ & $1(50)$ & $1(50)$ & $1.2(60)$ & 4 & $2(50)$ \\
\hline 27 & $\begin{array}{l}\text { Medicines acting on the ear, nose } \\
\text { and oropharynx }\end{array}$ & 9 & $5(56)$ & $2(22)$ & $2(22)$ & $3(33)$ & $3(33)$ & $3(33)$ & 9 & $4(44)$ \\
\hline \multirow[t]{2}{*}{28} & Specific medicines for neonatal care & 1 & $1(100)$ & 0 & 0 & 0 & 0 & $0.2(20)$ & 2 & $2(100)$ \\
\hline & Total (\%) & 165 & $134(81)$ & $105(64)$ & $96(58)$ & $52(32)$ & $78(47)$ & $112.6(56)$ & 251 & $179(71)$ \\
\hline
\end{tabular}

Duplication of medicines, in multiple categories of the national list of essential medicines, Sri Lanka (2013-2014), was left out of the calculation of availability (\%). N/A - These categories of the national list of essential medicines, Sri Lanka (2013-2014), are not applicable for primary care institutions. PCI Primary care institution, SCI Secondary care institution, $B H$ Base Hospital, DH District Hospital, PU Peripheral Unit, RH Rural Hospital, CD Central Dispensary 
ciprofloxacin eye drops. Medicines acting in nose (betamethasone nasal drop, silver nitrate crystals) were not found in any of the institutions selected for the study. Out of all institutions only $\mathrm{DH}$ had povidone iodine mouth-wash. Aqueous cream and emulsifying ointment were found only in $\mathrm{DH}$, even the secondary care institution failed to have it. Availability of anticonvulsants was $50 \%$ at the secondary care institution compared to the mean availability of $36 \%$ at the primary care institutions (Fig. 1). Availability of cardiovascular medicines was $89 \%$ at the secondary care institution compared to the mean availability of $70 \%$ at the primary care institutions (Fig. 2).

\section{Availability of medicines used in the management of chronic kidney disease}

Essential medicines involved in the management of chronic kidney disease were ferrous salt, iron sucrose, erythropoietin, vitamin D3 + calcium carbonate and calcitriol [19].

Erythropoietin and calcitriol are not expected to be available in primary or secondary care institutions. Rest was expected to be available at all levels of care. The secondary care institution $(\mathrm{BH})$ failed to have ferrous sulphate tablets used in the management of iron deficiency anaemia. In comparison 4 out of 5 primary care institutions (DH, PU, RH, CD-2) have had ferrous sulphate tablets. Intravenous iron preparation (iron sucrose) was not found in any of the institutions. Vitamin $\mathrm{D} 3$ + calcium carbonate was found only in $\mathrm{DH}$.

Anti-hypertensive medicines expected to be available at primary and secondary care levels were atenolol, enalapril, hydrochlorothiazide, methyldopa and nifedipine. Except for hydrochlorothiazide and methyldopa, all other are used in chronic kidney disease. Secondary care institution had all of them. Methyldopa, used to treat pregnancy induced hypertension was not available in PU, CD-1 and CD-2. However, all other anti- hypertensive medicines were found in all primary care institutions.

Furosemide, hydrochlorothiazide, mannitol and spironolactone are the diuretics expected to be available at a secondary care institution. $\mathrm{BH}$ had all of them. Out of the diuretics mentioned above, mannitol is not expected to be available at primary care institutions. DH, PU and RH showed $100 \%$ availability for diuretics. CD-1 had only hydrochlorothiazide. CD-2 had all except intravenous furosemide.

\section{Insulin and other anti-diabetic agents}

Biphasic insulin, metformin, glibenclamide and tolbutamide were expected to be available in primary care units. $\mathrm{DH}, \mathrm{PU}$ and $\mathrm{RH}$ had all of those drugs. CD-1 had metformin and glibenclamide. CD-2 in addition had tolbutamide. Soluble insulin is expected to be present in secondary care institutions in addition to the above medicines. $\mathrm{BH}$ had all of them.

\section{Drugs needed in the management of snake bite}

Snake anti-venom serum injection was available only at $\mathrm{BH}$ and $\mathrm{DH}$. Adrenaline, hydrocortisone and parenteral chlorphenamine, which are essential in the management of anaphylaxis following anti-venom serum administration, were available in all institutions surveyed.

\section{Antidotes (Table 3)}

Secondary care institution is expected to have activated charcoal, fuller's earth, acetylcysteine, atropine, flumazenil, DL-methionine, naloxone and pralidoxime; but fuller's earth was not available. Activated charcoal, fuller's earth, atropine, DL-methionine and naloxone were expected to be available in primary care units. Both CDs failed to have any of them, except for atropine at CD-1. $\mathrm{PU}, \mathrm{RH}$ and $\mathrm{DH}$ had activated charcoal and atropine. These two are essential in the management of organophosphate poisoning [20], the commonest poisoning of the agricultural areas in SL.

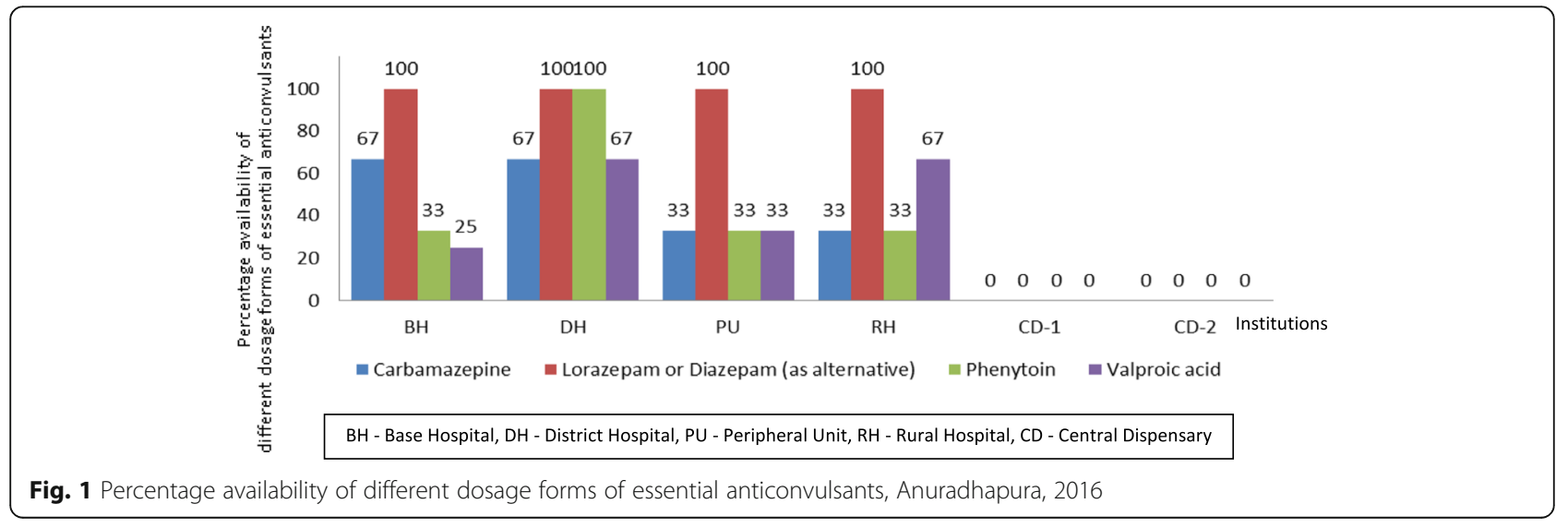






Fig. 2 Percentage availability of different dosage forms of essential cardiovascular medicines, Anuradhapura, 2016

\section{Discussion}

According to the WHO definition, essential medicines are expected to be available at all times within a functioning health system [1]. Our study mimicked a patient visiting a selected institution with a need of a particular essential medicine. This gives an insight to the availability of essential medicines in those selected institutions.

$\mathrm{DH}$ is the only health care institution to have a "high" availability of essential medicine. $\mathrm{BH}, \mathrm{PU}$ and $\mathrm{RH}$ had "fairly high" availability, whereas both the CDs had "low" availability. A national survey done in SL revealed an availability of $36.4 \%$ and $>50 \%$ respectively for primary and secondary levels of care. The above survey was on selected essential medicines used in non-communicable diseases [6]. Another national survey revealed 54, 49 and $45 \%$ as the mean availability of key essential medicines for children in district hospitals, peripheral hospitals and central dispensaries of SL [7].

Specialist units like ophthalmology, otorhinolaryngology, dermatology and neonatology are not available in primary or secondary care levels. Also number of deliveries is low in primary care institutions. These reasons 
Table 3 Availability of essential antidotes at selected primary and secondary health care institutions of Anuradhapura, 2016

\begin{tabular}{lllllll}
\hline Antidote & \multicolumn{3}{l}{ Institutions } & & & \\
\cline { 2 - 6 } & BH & DH & PU & RH & CD-1 & CD-2 \\
\hline Non-specific antidotes & & & & & & \\
Charcoal (Activated) & P & P & P & P & A & A \\
Fuller's earth & A & P & P & A & A & A \\
Specific antidotes & & & & & & \\
Acetylcysteine & P & NA & NA & NA & NA & NA \\
Atropine & P & P & P & P & P & A \\
Flumazenil & P & NA & NA & NA & NA & NA \\
DL-methionine & P & A & A & A & A & A \\
Naloxone & P & A & A & A & A & A \\
Pralidoxime & P & NA & NA & NA & NA & NA \\
\hline
\end{tabular}

$B H$ Base Hospital, $D H$ District Hospital, $P U$ Peripheral Unit, $R H$ Rural Hospital, $C D$ Central Dispensary, $P$ Present, $A$ Absent, NA Not applicable

could have contributed to the unavailability of essential medicines related to these specialities.

More than $70 \%$ of availability in $\mathrm{BH}$ and $\mathrm{DH}$ reflects larger number of patients utilizing services of these institutions. Although $\mathrm{BH}$ (a secondary care institution) has lower availability of analgesics and anti-infectives it is a relative unavailability compared to some primary care institutions and the essential list. Eight out of 12 analgesics and 32 out of 47 anti-infectives are available in $\mathrm{BH}$ compared to $6 / 6$ and $20 / 24$ in DH. Careful analysis of data (Additional file 1) displays that only some dosage forms of anti-infectives are not available in BH. Only the infrequently needed co-trimoxazole and clindamycin are not available in any form or strength. Among analgesics, only morphine sulphate tablets are not available in $\mathrm{BH}$. This may reflect lack of facility for palliative care. Availability of morphine sulphate tablets in the public sector was $4 \%$ in SL as reported by a study in 2007 [4].

Anuradhapura district is an endemic area for chronic kidney disease. Lack of availability of medicines related to chronic kidney disease was noted. Also a national list of essential medicine cannot address regional variation of pharmaceutical need and utilization. Certain medicines should be available in all levels of health care for some parts of the country. Tailoring the essential medicines to suit the needs of a particular region is suggested. Unavailability of intravenous iron even in a base hospital may suggest genuine unavailability or lack of utilization. Intravenous iron is most suitable for treatment of iron deficiency in chronic kidney disease and rapid treatment in de novo iron deficiency. Overall, Availability of medicines needed for the management of hypertension and diabetes was commendable. Availability of anti-diabetics from a previous national survey in SL was nearly $60 \%$ in public hospitals [6]. The same survey revealed an availability ranging from 37 to $100 \%$ for antihypertensive medicines.

Snake anti-venom serum injection was available only at $\mathrm{DH}$ among the primary care institutions. Considering the higher prevalence of venomous snake bites in SL dry zones [21] this situation needs to be rectified immediately. Higher mortality ratescan be reduced to a certain extent by preventing unnecessary delay in starting the anti-venom serum. This situation is despite the fact that all institutions had medicines needed for managing anaphylactic shock following anti-venom serum administration. However the efficacy of Indian anti-venom serum (VINS and BHARAT are used in SL) against SL snake venom is questionable [22].

Atropine, the antidote for organophosphate was available in all health care institutions except CD-2. A study conducted in Anuradhapura has shown that pesticides were the commonest $(1572 / 3813-41 \%$ of total admissions due to poisoning) agents for poisoning followed by pharmaceuticals ( $21 \%$ of total admissions due to poisoning) [23]. However the same study also shows that the pattern of deliberate self-harm is changing with increased use of pharmaceuticals. This mandates availability of wider range of antidotes. Unavailability of fuller's earth in most institutions may be due to the banning of the specific poisoning "paraquat" since 2010.

Both the CDs have shown unavailability of certain anticonvulsants and antidotes which are needed for the management of medical emergencies (Table 3, Fig. 1). The concept of having four levels of care encourages initial management and stabilization of an acutely ill patient at the first contact. Uninterrupted supply of essential medicines used in emergencies is needed to achieve this goal.

Chlorhexidine solution for umbillical cord care was available only at $\mathrm{DH}$ among the primary care institutions. According to WHO recommendations "daily chlorhexidine $(7.1 \%$ chlorhexidine digluconate aqueous solution or gel, delivering $4 \%$ chlorhexidine) application to the umbilical cord stump during the first week of life is recommended for newborns who are born at home in settings with high neonatal mortality (30 or more neonatal deaths per 1000 live births). Clean, dry cord care is recommended for newborns born in health facilities and at home in low neonatal mortality settings. Use of chlorhexidine in these situations may be considered only to replace application of a harmful traditional substance, such as cow dung, to the cord stump" [24]. Neonatal mortality in Anuradhapura is 24 neonatal deaths per 1000 live births according to the latest available data [25]. Institutional delivery rate in SL is more than $98 \%$ [26]. The above facts justify the non-usage of chlorhexidine and may have been the reason for unavailability. Also when there are no deliveries or neonatal care in 
certain hospitals (CD-1 and CD-2), medicines related to pregnancy (such as methyldopa in pregnancy induced hypertension) and neonatal care (such as chlorhexidine in umbilical cord care) may not be needed.

Tropicamide eye drops are not available in any of the surveyed institutions. They are being used to dilate the pupils for examination of retina [27]. Retinopathy survey in diabetes seems to be absent in any of the surveyed institutions.

The national list of essential medicines was written exclusively by experts based at Colombo, an urban capital district of SL. "Experts" may not be available from the rural areas. However, inputs from prescribers working in rural areas may enhance the list of essential medicines and make it more relevant for prescribers in rural areas. Also having a separate list of essential medicines, for primary care institutions which do not have inward facilities, is suggested.

The concept of "essential medicines" is yet to be followed by the individual heads of health care institutions. Unavailability of certain medicines may be due to non-utilization of those medicines by prescribers. Medicines are supplied purely on the annual estimates prepared by the relevant institutions based on usage in the previous year. This would predict the quantity needed for the following year but will fail in making available all varieties of the essential medicines. Continuous medical education is needed to enlighten prescribing doctors on the importance of utilizing medicines available in the national list of essential medicines.

Regardless of all these short coming SL has achieved health indices comparable to developed countries [8] and many nationwide studies have also shown a "fairly high" availability of essential medicines in SL $[4,6]$ which was supported by this survey too.

\section{Conclusions}

Overall availability of essential medicines at the selected institutions was fairly high. It was high at $\mathrm{BH}$, a primary care institution, and low at both the CDs. There is concern in the availability of antidotes, snake anti-venom and medicines used in the management of chronic kidney disease. However availability of anti-hypertensive medicines, anti-diabetics and diuretics was commendable yet there is room for improvement. This will reduce not only the overcrowding at tertiary care institutions but also the indirect health care cost for rural residents. Amalgamating the concept based "essential medicines" with the need based "annual estimates" is suggested for improving the availability of essential medicines.

\section{Additional file}

Additional file 1: Availability of essential medicines in a rural Sri Lankan district, 2016. This provides the results of the entire survey with data for each essential medicine. (XLS $187 \mathrm{~kb}$ )

\section{Abbreviations}

BH: Base Hospital; CD: Central Dispensary; DH: District Hospital; HAl: Health Action International; PU: Peripheral Unit; RH: Rural Hospital; SL: Sri Lanka; WHO: World Health Organization

\section{Acknowledgements}

Not applicable.

Funding

The study was self-funded.

Availability of data and materials

All data generated or analysed during this study are included in this published article (and its supplementary information files).

\section{Authors' contributions}

DR conceived the idea of the study and all authors participated in designing the study. IP, TJ, CK, KP, LA and TB were involved in data collection. DR, IP, TJ, CK, KP, LA and TB were involved in the analysis of data. All authors were involved in interpretation of data. DR, IP and TJ drafted the manuscript and SS, CJ, CK, KP, LA and TB critically revised it. All authors read and approved the final manuscript.

\section{Competing interests}

The authors declare that they have no competing interests.

\section{Consent for publication}

Consent to publish the information gathered from each institutions was obtained, provided that it will not be possible to identify individual institutions in any way.

\section{Ethics approval and consent to participate}

Ethical clearance was obtained from the Ethics Review Committee of FMAS, RUSL (ERC/2016/72). Administrative clearance was obtained from the regional director of health services of the particular district. Institutional permission was obtained from all relevant directors, district medical officers and medical officers in charge of each of the institutions.

\section{Author details}

${ }^{1}$ Department of Pharmacology, Faculty of Medicine and Allied Sciences, Rajarata University of Sri Lanka, Saliyapura, Sri Lanka. ${ }^{2}$ Department of Medicine, Faculty of Medicine and Allied Sciences, Rajarata University of Sri Lanka, Saliyapura, Sri Lanka.

Received: 27 October 2016 Accepted: 22 December 2016

Published online: 05 January 2017

\section{References}

1. Essential medicines and health products. Geneva: World health organization. 2016. [cited 2016 Jul 01]. Available from: http://www.who.int/ medicines/services/essmedicines_def/en/.

2. WHO Medicines Strategy 2004-2007. Geneva: World health organization. 2004. [cited 2016 Jul 01]. Available from: http://apps.who.int/medicinedocs/ en/d/Js5416e/.

3. Cameron A, Ewen M, Ross-Degnan D, Ball D, Laing R. Medicine prices, availability, and affordability in 36 developing and middle-income countries: a secondary analysis. Lancet. 2009:373:240-9.

4. Mendis S, Fukino K, Cameron A, Laing R, Filipe A, Khatib O, Leowski J, Ewen $M$. The availability and affordability of selected essential medicines for chronic diseases in six low and middle-income countries. Bull World Health Organ. 2007:85:279-88.

5. Senarathna SMDKG, Mannapperuma U, Fernandopulle BMR. Medicine prices, availability and affordability in Sri Lanka. Indian J Pharmacol. 2011;43:60-3.

6. Dabare PRL, Wanigatunge CA, Beneragama B. A national survey on availability, price and affordability of selected essential medicines for noncommunicable diseases in Sri Lanka. BMC Public Health. 2014;14:817.

7. Balasubramaniam R, Beneragama B, Ranganathan SS. A national survey of availability of key essential medicines for children in Sri Lanka. Ceylon Med J. 2011;56:101-7.

8. WHO Sri Lanka. Geneva: World health organization. 2016. [cited 2016 Jul 01] Available from: http://www.who.int/countries/lka/en/. 
9. Sri Lanka's healthcare challenges. London: The economist intelligence unit. 2014. [cited $2016 \mathrm{Jul}$ 01]. Available from: http://country.eiu.com/article. aspx?articleid $=1502512534 \&$ Country=SriLanka\&topic $=$ Economy\&subtopic $=$ Forecast.

10. Curative Care Services. Kandy: Dept. of Health Services: Central Province, Sri Lanka. 2016. [cited 2016 Jul 01]. Available from: http://www.healthcpc.org/ index.php?option=com_content\&view=article\&id=48\&ltemid=34.

11. Fernandopulle BMR, Samarasinghe SVAC, Abeyawardena C, Wickremasinghe R. Availability, price and affordability of selected medicines for treatment of NCDs in Sri Lanka. $128^{\text {th }}$ Annual Scientific Sessions, Sri Lanka Medical Association, Colombo, Sri Lanka.2015.

12. Census of Population and Housing. Colombo: Department of Census and Statistics, Ministry of Finance and Planning. 2012.

13. Annual Bulletin, Sri Lanka Labour Force Survey. Colombo: Department of Census and Statistics, Ministry of Finance and Planning. 2014.

14. Household Income and Expenditure Survey. Colombo: Department of Census \& Statistics, Ministry of Policy Planning Economic Affairs, Child Youth and Cultural Affairs. 2013.

15. Measuring Medicine Prices, Availability, Affordability and Price Components. $2^{\text {nd }}$ edition. Geneva: World Health Organization. 2008.

16. National List of Essential Medicines Sri Lanka. Ministry of Health, Sri Lanka. 2014.

17. WHO Model List of Essential Medicines. Geneva: World Health Organization. 2015.

18. Gelders S, Ewen M, Noguchi N, Laing R. Price, Availability and Affordability: An International Comparison of Chronic Diseases Medicines. Cairo; 2006.

19. Pradeep A et al. Chronic Kidney Disease Treatment \& Medication. Medscape. 2016 [cited 2016 Dec 15]. Available from: http://emedicine. medscape.com/article/238798-medication.

20. Kenneth DK et al. Organophosphate Toxicity Treatment \& Management. Medscape. 2016. [cited 2016 Dec 15]. Available from: http://emedicine. medscape.com/article/167726-treatment.

21. Kasturiratne A, Pathmeswaran A, Fonseka MMD, Lalloo DG, Brooker S, De Silva $\mathrm{HJ}$. Estimates of disease burden due to land-snake bite in Sri Lankan hospitals. Southeast Asian J Trop Med Public Health. 2005;36:733-40.

22. Maduwage K, Silva A, O'Leary MA, Hodgson WC, Isbister GK. Efficacy of Indian polyvalent snake antivenoms against Sri Lankan snake venoms: lethality studies or clinically focused in vitro studies. Sci Rep. 2016;6:26778.

23. Senarathna L, Jayamanna SF, Kelly PJ, Buckley NA, Dibley MJ, Dawson AH. Changing epidemiologic patterns of deliberate self poisoning in a rural district of Sri Lanka. BMC Public Health. 2012;12:593.

24. WHO Recommendations on Postnatal Care of the Mother and Newborn. Geneva: World Health Organization. 2013.

25. Lanka Demographic and Health Survey 2006-07. Colombo: Department of Census and Statistics, Ministry of Healthcare and Nutrition. 2009.

26. Sri lanka and Niger. UNICEF. 2007. [cited 2016 Jul 01] Available from: http:// www.unicef.org/sowc09/docs/SOWC09-CountryExample-SriLankaNiger.pdf.

27. Tropicamide. Medscape. 2016. [cited 2016 Dec 15] Available from: http:// reference.medscape.com/drug/mydriacyl-tropicacyl-tropicamide-343616.

\section{Submit your next manuscript to BioMed Central and we will help you at every step:}

- We accept pre-submission inquiries

- Our selector tool helps you to find the most relevant journal

- We provide round the clock customer support

- Convenient online submission

- Thorough peer review

- Inclusion in PubMed and all major indexing services

- Maximum visibility for your research

Submit your manuscript at www.biomedcentral.com/submit

) Biomed Central 